\title{
ANALYSES
}

Article received on 20 November 2012

Article accepted on 30 November 2012

UDC: 78.071.1 Дебиси К.

\section{ONTOLOGY OF SPACE IN CLAUDE DEBUSSY'S SHEET MUSIC}

\author{
Svetlana A. Mozgot* \\ Institute of Arts \\ Adyghe State University \\ Maikop, Russia
}

Background. Debussy's sheet music is a unique phenomenon showing the transformation of musical spatial characteristics into a graphic equivalent. This paper suggests a new elementalist approach to studying the spatial properties of musical sound. This approach enables musicologists and performers to create a new interpretation of sheet music and to discover a new musical content in a score.

Aim: to show techniques which C. Debussy used to fix spatial characteristics in the printed music and to show how the physical properties of space namely mass, volume and density of sound - become the carriers of the artistic sense in C. Debussy's notation.

Objectives: to show the technique of marking the sound mass; ways of decreasing the weight of sound; transformation of the mass of sound into the volume of sound and the different density of sound.

Methods of study. We used a musicological analysis to reveal the techniques of sound articulation typical of C. Debussy. The new approach of musi-

*Author contact information: prostranstvo30@yandex.ru 
cological elementalism was used to study musical sound in terms of its spatial features, namely its mass, volume and density. Musicology adopted the elementalist approach from personal psychology. Scientists used it to study personal nature in terms of every individual component of a person's behaviour, from simple to composite. We continue this tendency and use this approach in this item. A comparative method was used to find out the distinctions between mass, volume and density of sound. The axiological approach and semantic approach were used to study the expressive properties of mass, volume and density in the artistic content.

Discussion. 1. The concept of the mass of sound.

The concept of the mass of sound was included in musical science in the second half of the $20^{\text {th }}$ century. The mass of sound is a feeling of its weight which, according to E. Kurt [3], is stronger when listening to a chord compared to one sound. According to C. Stumpf [1], the mass of sound is an impression which depends on the process of acoustic fluctuations, and according to $\mathrm{H}$. Riemann [3], the mass of sound emerges by playing the same sound on different instruments. We see different approaches to the study of musical sound, such as the psycho-physiological, acoustic and intonation phenomena. Regarding this, we shall use the terms of E. V. Nazaykinsky [5], who considered musical sound to be a phenomenon of an acoustic order, tone as a factor of intonation, and a note as a symbol of graphic fixing.

The means of marking the weight of sound in the scores of C. Debussy include: the accent; the accent with sforzando; the accent with the author's remarks + tenuto, marcato; and the displacement of the weight of sound onto the unstressed part of the bar.

We have noticed that C. Debussy used articulation marks as a means of the intentional representation of different weights of musical sounds. This intention of the composer has raised many questions in performing art. Thus, Louis Laloy considered that the line under the note was a sign meaning that a transparent sound was required. For M. Long it was 'a sudden pressure' (attacca) - 'the weight of sound' [4]. In our opinion, Debussy designated lines over or under the note to show the middle weight and depth of tone sounding.

In C. Debussy's prelude La sérénade interrompue we can see that the last notes in the first and third bars, respectively, are accented. This accent was made for decoration, to show the unique spirit and image of Spain in many Spanish works by Debussy: orchestral suite Iberia, La soirée dans Grenade, preludes La sérénade interrompue, La puerta del Vino, the piece for two pianos Lindaraja, and the second movement (Sérénade) of the Sonata for violoncello and piano. 


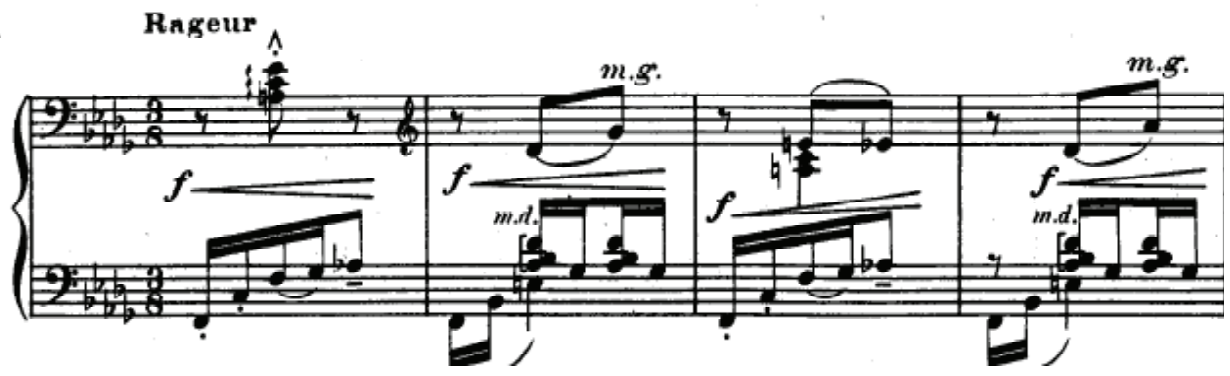

The accent with sforzando. In C. Debussy's prelude Feux d'artifice (middle of the bar 2), sforzando is a dynamic gesture. It emphasizes the weight, as well as the colour of the sound register, and creates the effect of an approaching object.

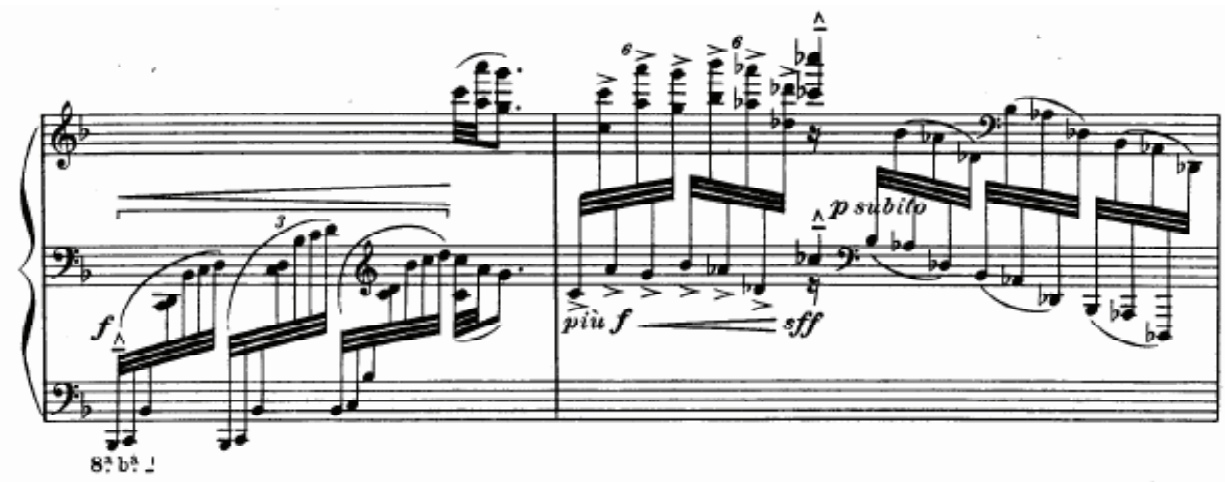

In the piece Mouvement from the cycle Images, C. Debussy used the accent with the author's remarks.

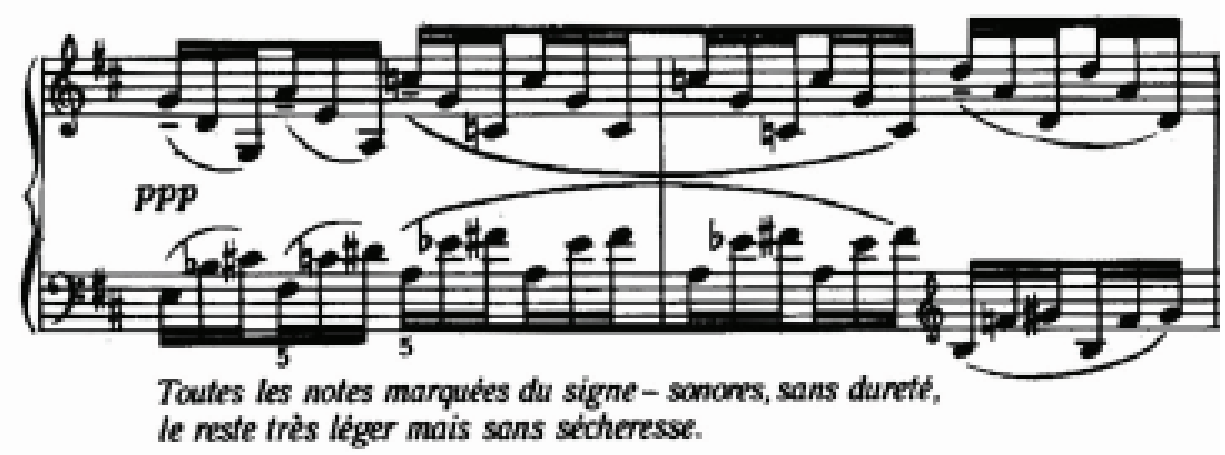


C. Debussy wanted the performer to play all the accented notes as sonorous sounds but without rigidity, while the other notes should be played very lightly, but without dryness (C. Debussy). In the artistic sense, the sonorous sound shows the image located in proximity, at the foreground.

C. Debussy used the accent with tenuto in the second movement (Sérénade) of the Sonata for violoncello and piano (the last bar of the example).

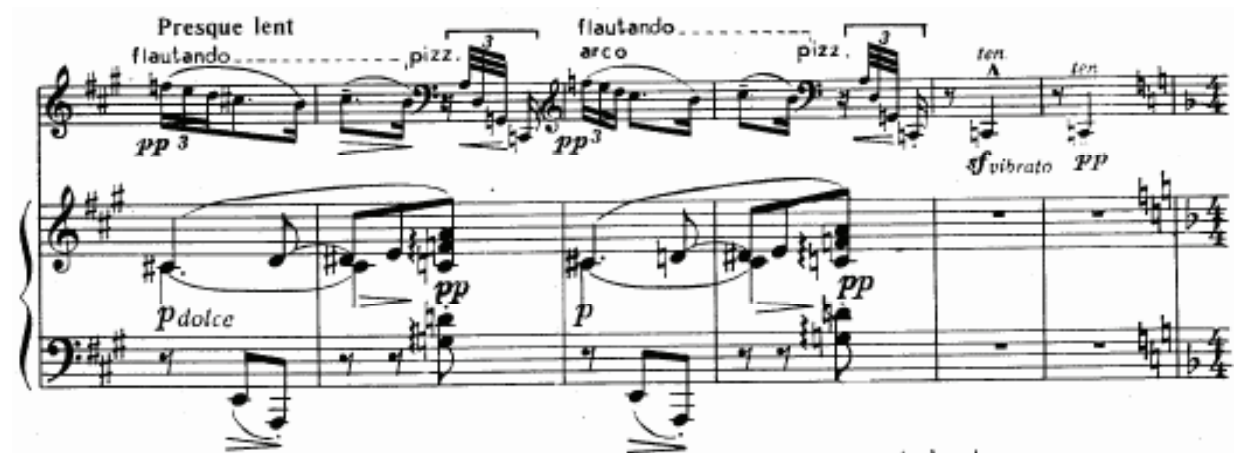

The author's remark tenuto with the accent makes the sound heavier. The weight of sound stops movement, and it functions as a formal delimiter to prepare the coda.

The next marking of the sound weight can be found in C. Debussy's piece for two pianos Lindaraja. The composer displaces the weight of sound onto the unstressed part of the bar (the piano II part).

C. Debussy places a stress onto the unstressed part of the bar to show not

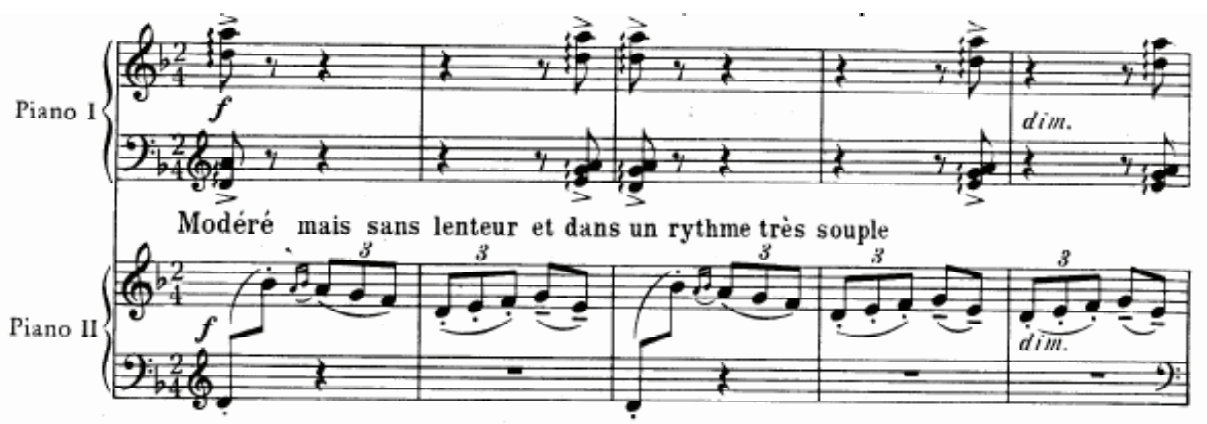

only the original shape of dance but also the latent possibility for the development in this piece.

This technique plays a dramaturgic role and is used in the culmination of Lindaraja. 


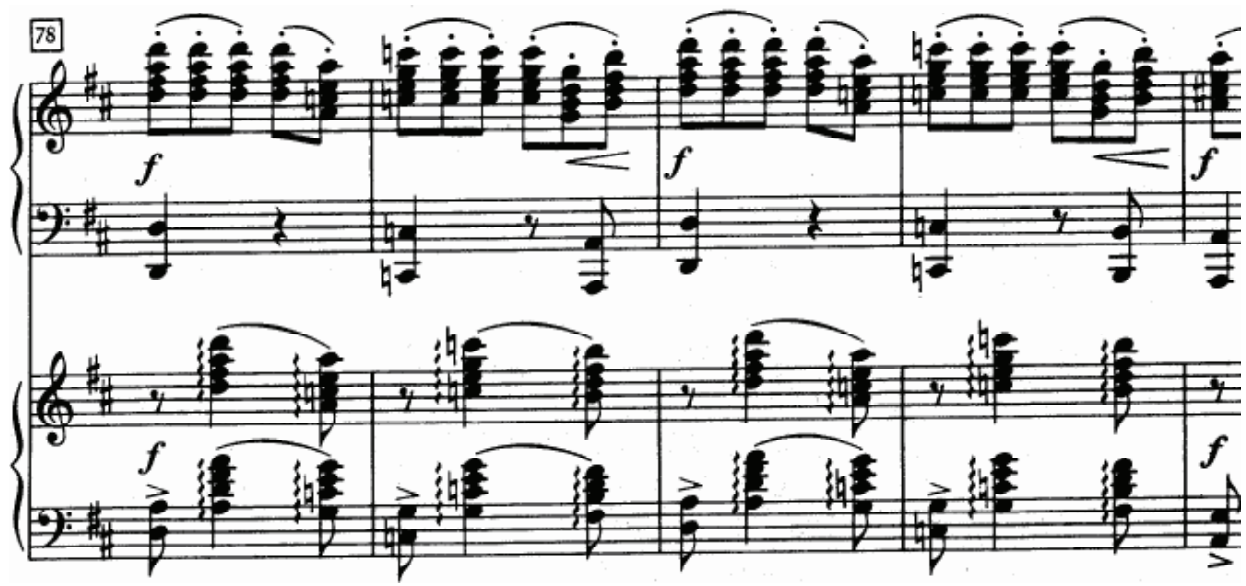

In Debussy's Sonata for violoncello and piano the weight of sound shows the increasing importance of the vertical component and plays a dramaturgic and form-building role, preparing the next cadence of the violoncello.

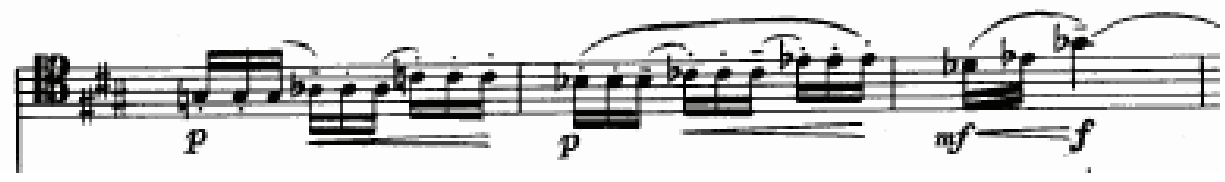

Apart from the articulation conveying a certain resolution of the performer in the achievement of the artistic sense, the type of instrument influences essentially the feeling of the weight of sound in Debussy's music. For example, in Debussy's works written in the tradition of the French clavecinists, musicians should consider how the sounds would be produced on the harpsichord in order to achieve the correct touch. At the same time, Debussy's later works - Préludes 2ème livre and Études - are reminiscent of orchestral transcriptions. In order to perform them, the pianist at first has to overcome a feeling that he or she "is missing a third hand'. Debussy himself said that his Études can be perceived as a collection of exercises if the musician, while studying them, is guided only by technical problems. Leon Walla has noticed that it was no coincidence that Debussy chose the genre of the prelude for musical 'sketches'. Debussy considered them to be short introductions to more important works written in the same way, rather than compositions for independent performance. Knowing this feature of the composer's mature style, the musician has the right to correlate the 
chosen piano touch to the features of sound produced on various instruments of the symphony orchestra [6].

\section{The ways to decrease the mass of sound}

Studying the laws of assigning weight to a tone as an objective in Debussy's opus, we understand that the aim of the composer's sound creation is to overcome the weight of tone, instead of to allot it.

C. Debussy defined several ways in which to decrease the mass of sound: softening the attack of sound; softening the attack of sound by using appoggiaturas or other ornaments; the employment of sounds in extreme registers.

In the movement Jeux de vagues of the symphonic composition La mer, Debussy softened the attack of sound using a closed sound in the wind instruments, marked by the word bouchez. This technique leaves the impression of a distant background.

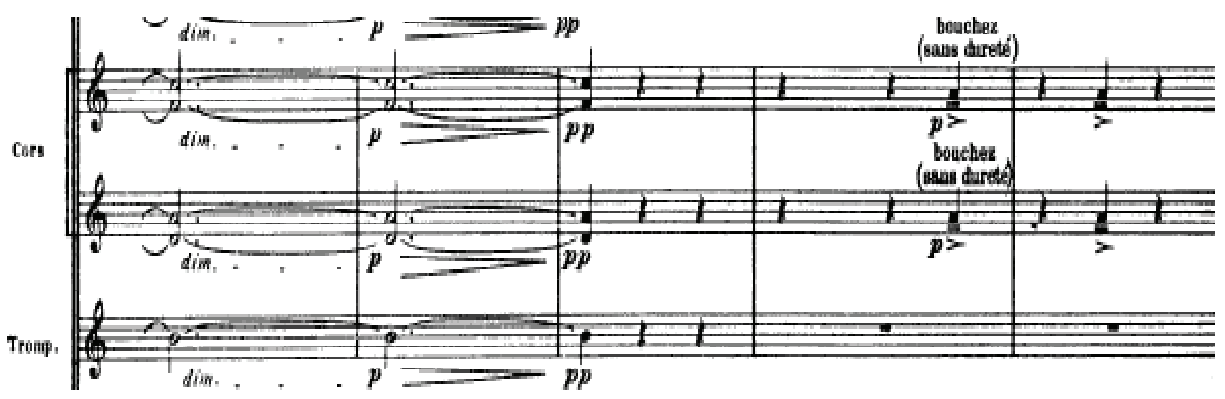

In most cases, C. Debussy softened the attack of sound using legato, arpeggiated chords, dynamic markings and ornaments.

In the piece Et la lune descend sur le temple qui fut from the cycle Images (2ème série), C. Debussy uses the special form of an octave appoggiatura,

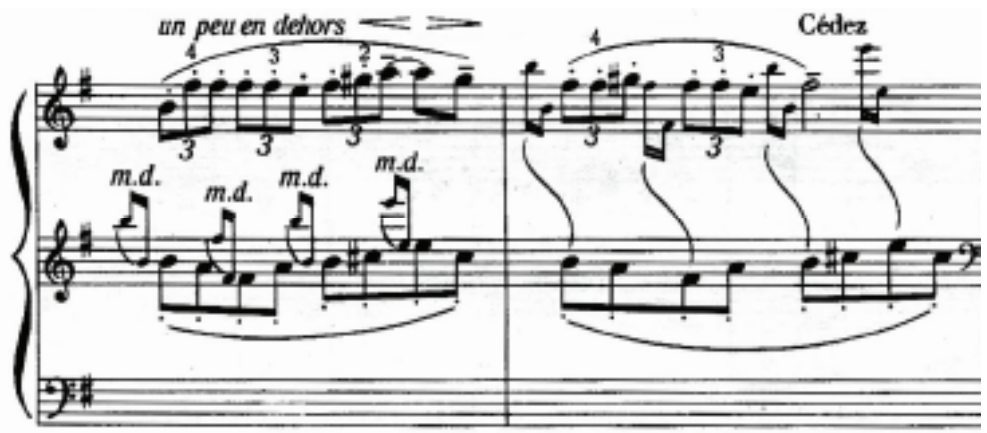


transforming the mass of sound into volume, which is achieved owing to the effect of chiming. The sound becomes flowing and flying.

In Debussy's prelude Feux d'artifice, the interval of five octaves between the melody and the bass, as well as the tremolo in the bass, decreases the weight of the sounds. Debussy created the image of smoke filling up the night sky of Paris.

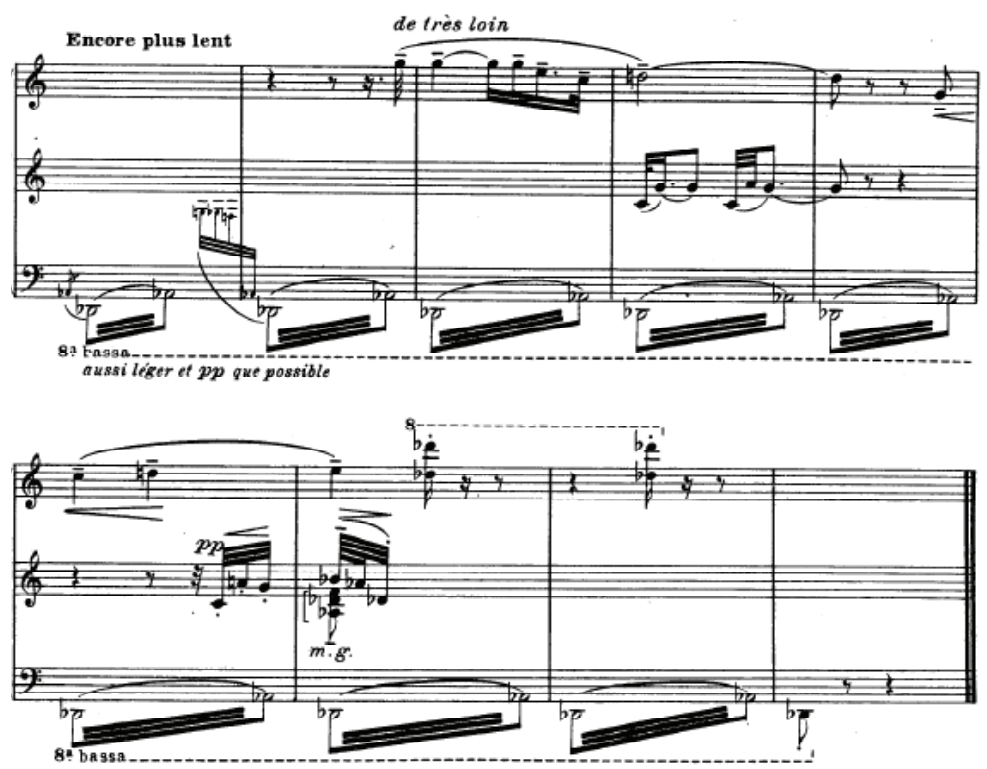

3. The concept of the volume of musical sound and ways of transforming the mass of sound into the volume

The volume of sound depends on the quantity of natural harmonics that express the possibilities of sound to flow, reverberate, grow and diminish in personal perception. The ways of transforming the mass of sound into the volume are as follows: the long note with a gradual increase or decrease of the sound dynamics, and drawing attention to the sound's natural harmonics and their projection on the music substance.

In each section of the symphonic piece Prélude à l'après-midi d'un faune (flute solos at the beginning, at rehearsal number 2, at rehearsal number 9), the first sound of the musical theme becomes longer, showing the breadth of the music. 
Solo flute at the beginning:

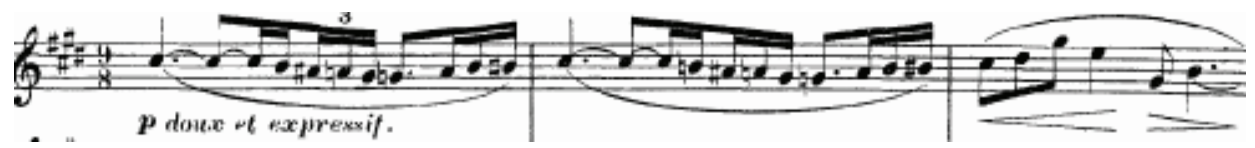

Rehearsal number 2:

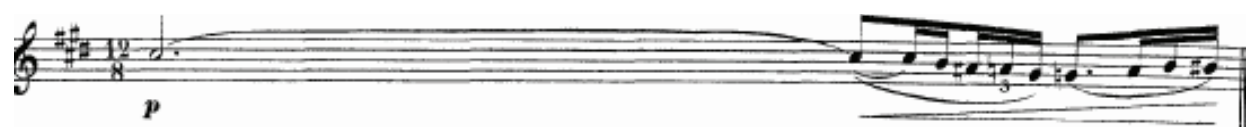

Rehearsal number 9:

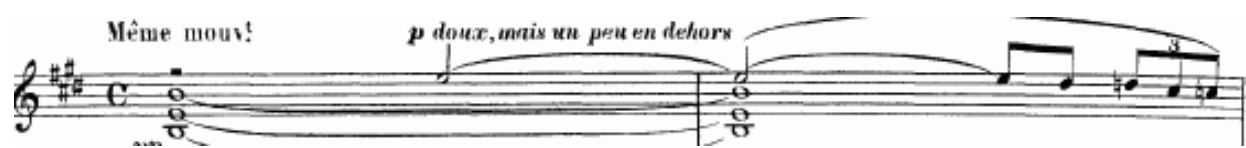

Another way of transforming the mass of sound into the volume is drawing attention to the sound's natural harmonics and their projection on the music substance. In the movement De l'aube à midi sur la mer of the symphonic work La mer, C. Debussy builds the introduction by recreating the natural harmonic scale and leaning on consonances: an octave, a fourth, a fifth and a third. They strengthen the intensity of merging and underline the effect of the natural harmonic resonance that creates the impression of increasing volume.

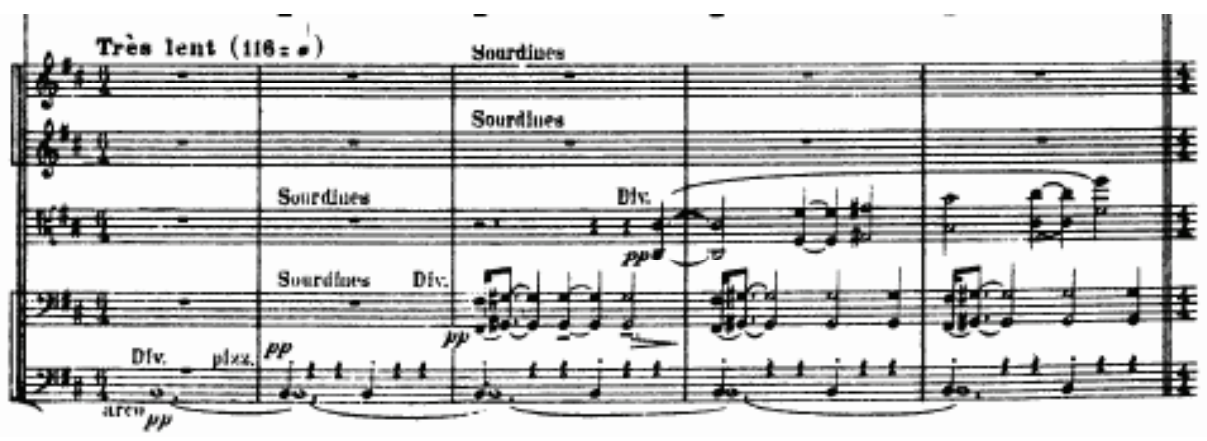




\section{The concept of density of musical sound}

Density of sound is the sensation of the structure of musical sound. The density of sound depends on the richness of the natural harmonic spectrum, register, timbre and on the attack of a sound. In the artistic content, this is expressed through the metaphor of lightness, volatility and the non-material essence of musical sound. Ways to designate the different density of sound include the use of a flageolet; the use of a trill and a tremolo; and the use of a trill with a long note.

At the end of the Prologue of the Sonata for violoncello and piano, Debussy used a flageolet. Here, the main tone becomes inaudible and only natural harmonics are heard, while their timbre acquires a special peculiarity. The artistic sense of flageolet in the high register has the effect of dissolving, transparency and great distance.

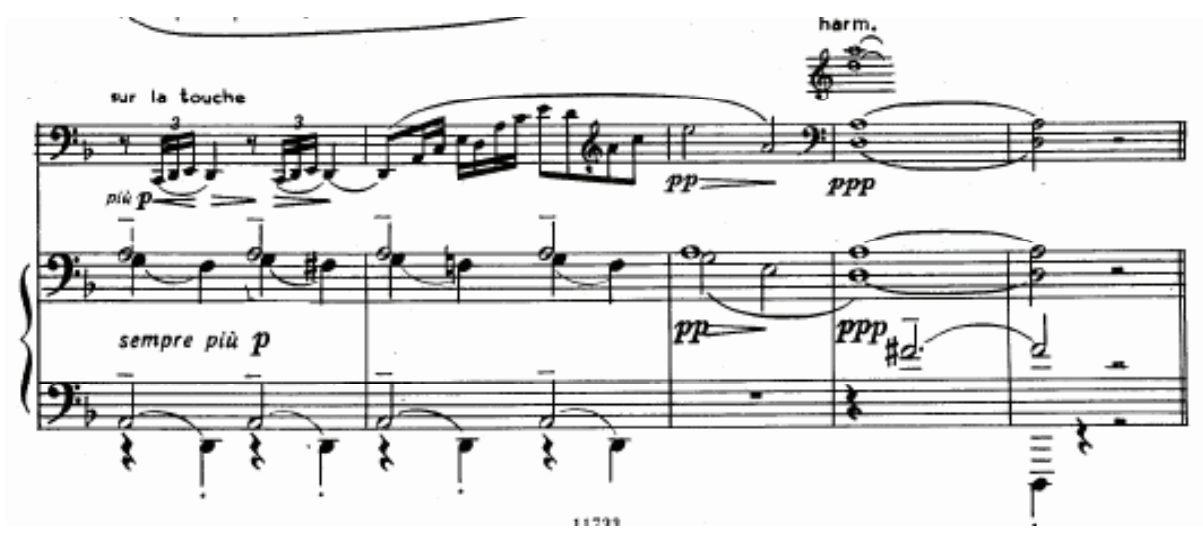

In bar 2 of the next example from the ballet Jeux (bar 78 in the score), we can see the marking 'quasi trillo', whereas the notation implies a tremolo. A few words must be said here about the process of vibrato. Vibrations as an acoustic process emphasize the harmonic structure of a musical sound. A trill and tremolo are note analogues of this process. Changes of pitch during the natural vibrato of voice are almost inaudible. Such a vibrato is measured in one-hundredths of a semitone (i.e. in cents). The employment of trills allows the vibration to be heard, to be measured already in semitones or whole tones. The density of trill vibration becomes evident. The use of tremolo leads to a decreasing density. The remark 'quasi trillo' in this example shows that the tremolo should be played as densely as a trill. 


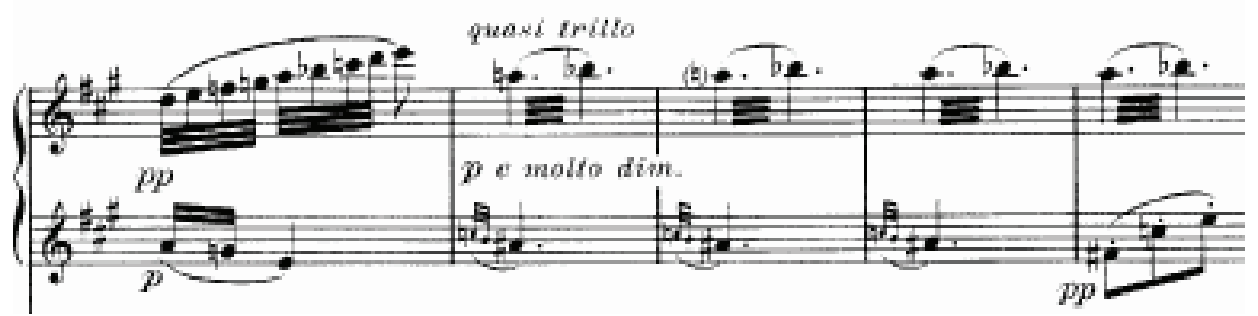

In the piece L'isle joyeuse, Debussy presented different densities of sound using a trill with a long tone. The gradual increase in the dynamics of a long tone by using a trill promotes the sensation of an approaching object and increases the volume and density. This technique is used as a factor of dramaturgic development.
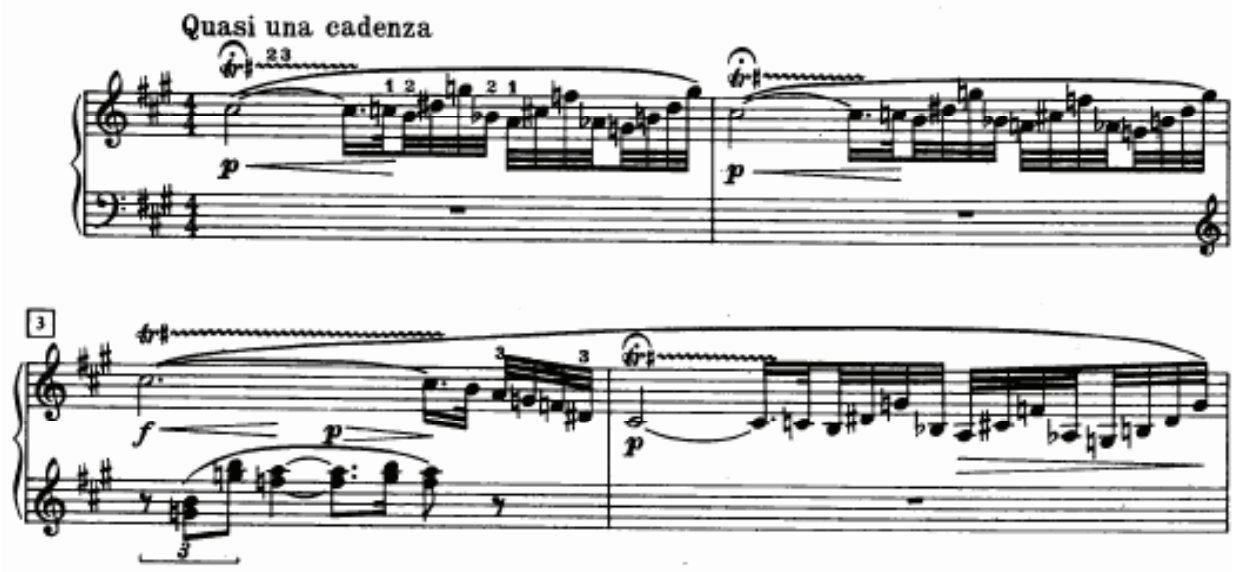

\section{Conclusion}

Debussy's printed scores are a unique phenomenon showing the transformation of musical spatial characteristics into a graphic equivalent. Each gesture has its own artistic and spatial meaning. The use of the new elementalistic approach to the study of the means of musical expression enables musicologists and performers to disclose a new music content and to give a new interpretation to the sheet music. 


\section{References:}

1. Braudo I. A., Articulation (On pronunciation of melody). Leningrad, Muzyka Publishing House, 1973. 199 p.

2. Korykhalova N. P., Musical terms for performers. The origin, development of meanings and their shades, the use in different styles. Saint Petersburg, Kompositor Publishing House, 2000. 272 p.

3. Kurt E., Romantic harmony and its crisis in Wagner's 'Tristan'. Moscow, Muzyka Publishing House. 1975. $551 \mathrm{p}$.

4. Long M., At the piano with Debussy. Moscow, Sovetsky Kompozitor Publishing House, 1985. $158 \mathrm{p}$.

5. Nazaykinsky E. V., On the psychology of musical perception. Moscow, Muzyka Publishing House, 1972. 372 p.

6. Vallas L., Claude Debussy et son temps. Paris: Alcan, 1932. 473 p. 